\title{
Conf. $9410329--1$
}

UCRL-JC-118743

PREPRINT

\section{Potential for Use of All-MOX Fuel in Existing and Evolutionary/Advanced LWRs in the United States}

\author{
Carl E. Walter
}

This paper was prepared for discussion at the

NATO Advanced Research Workshop

"Mixed Oxide Fuel (MOX) Exploitation and Destruction in Power Reactors"

Obninsk, Russia

October 16-19, 1994

September 27, 1994

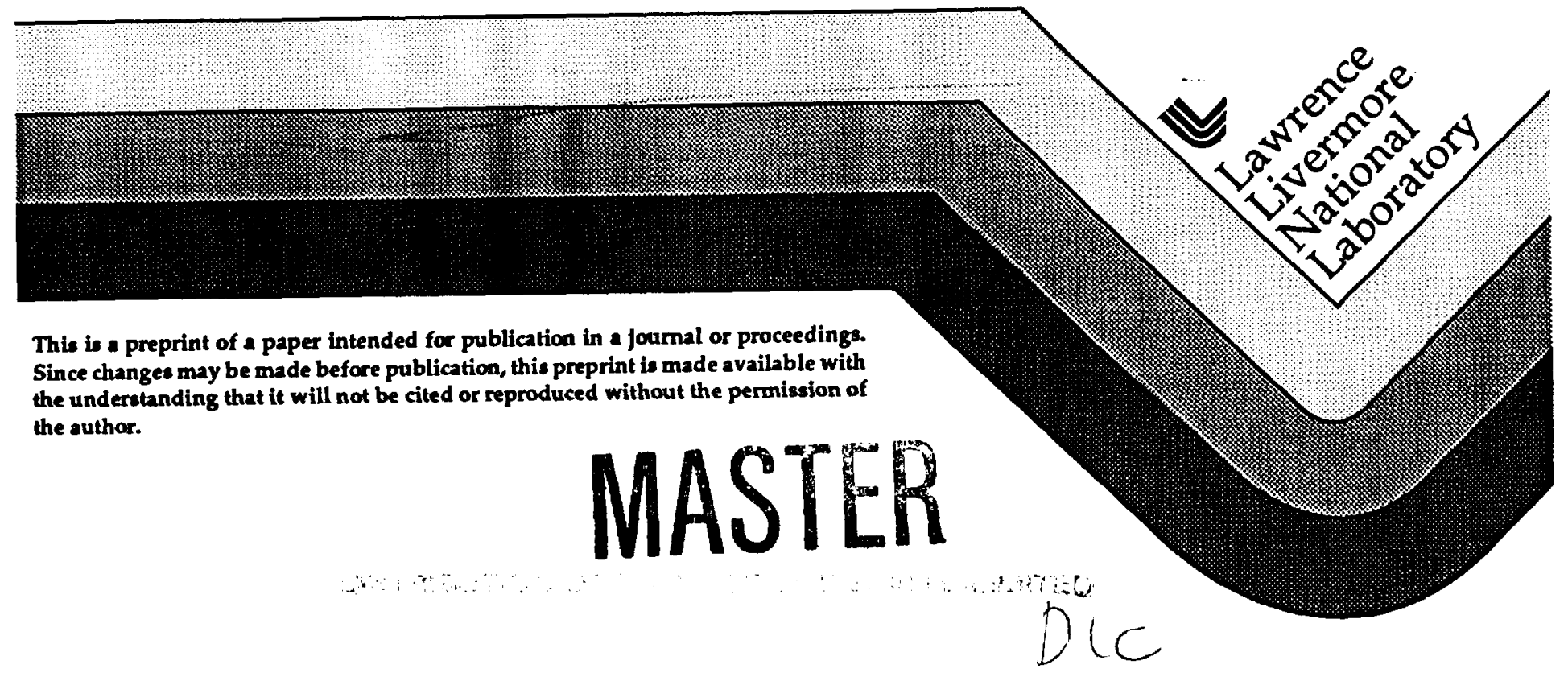




\section{DISCLAIMER}

This document was prepared as an account of work sponsored by an agency of the United States Government. Neither the United States Government, nor the University of California, nor any of their employees makes any warranty, express or implied, or assumes any legal liability or responsibility for the accuracy, completeness, or usefulness of any information, apparatus, product, or process disclosed, or represents that its use would not infringe privately owned rights. Reference herein to any specific commercial products, process, or service by trade name, trademark, manufacturer, or otherwise, does not necessarily constitute or imply its endorsement, recommendation, or favoring by the United States Government or the University of California. The views and opinions of authors expressed herein do not necessarily state or reflect those of the United States Government or the University of California, and shall not be used for advertising or product endorsement purposes. 


\title{
Potential for Use of All-MOX Fuel in Existing and Evolutionary/Advanced LWRs in the United States
}

\author{
Carl E. Walter \\ Lawrence Livermore National Laboratory \\ Obninsk, Russia \\ October 17, 1994
}

\section{Introduction}

Disposition of excess weapon plutonium following the end of the cold war and execution of the strategic arms reduction treaties between the United States and Russia has been a topic of great interest in the United States for some time. At Lawrence Livermore National Laboratory, we began to study methods for disposing of not only plutonium but highly enriched uranium late in 1991. Activities in this area were stimulated by a session ${ }^{1}$ chaired by $\mathrm{Dr}$. William Sutcliffe, also with us today, at the annual meeting of the American Association for the Advancement of Science (AAAS) in February 1991.

Our Laboratory studies led to a draft report ${ }^{2}$ in December 1992 that examined various plutonium disposition methods, grouped as storage, disposal, and fission. During this period, the Department of Energy (DOE) established a Plutonium Disposition Task Force comprising three committees to consider these specific disposition methods and a fourth committee to consider the associated nonproliferation issues. A report ${ }^{3}$ of the fission committee, of which I was a member, was published in February 1993. The committee examined the capability of reactors to use excess weapon plutonium as fuel and thus destroy or significantly alter its properties. By doing so, the risk that excess weapon plutonium would be diverted for clandestine or overt fabrication of nuclear explosives is considered to be greatly reduced. The uniqueness of weapon plutonium is lost when it is contained in spent fuel discharged from the reactor. In that condition the isotopic composition of plutonium is similar to that in spent fuel from the world's power reactors, Reference 3 was the only publication that resulted from the work of that DOE task force. 
DOE subsequently funded a new, more extensive study by U.S. reactor designers of evolutionary and advanced reactors to investigate the capability of their new designs to burn weapon plutonium and thus produce spent fuel having various characteristics, such as meeting a radiation standard in the shortest time possible ("spiking"), achieving most economical reactor operation ("spent fuel"), or achieving maximum destruction of plutonium ("destruction"). Two of several pertinent conclusions from the study ${ }^{4}$ of these alternatives, published in July 1993, are that (1) spent fuel is the most practical way to dispose of weapon plutonium, and (2) subsequent study should examine the use of existing light water reactors (LWRs) to use MOX fuel, thus reducing cost and, more importantly, accelerating the disposition of plutonium. The urgency to dispose of weapon plutonium was recognized.

In the meantime, the U.S. National Academy of Sciences (NAS) studied the disposition of excess weapon plutonium in the context of all the plutonium contained, and projected to be contained, in commercial spent fuel. The NAS report, ${ }^{5}$ published in February 1994, concludes that there is little to be gained in seeking to annihilate excess weapon plutonium, unless similar steps are taken with respect to the already much greater quantity of plutonium in commercial spent fuel. This conclusion is based on the generally held concern that nuclear explosives can be constructed from commercial spent fuel. Thus, the NAS study also advocates that achieving the "spent fuel" standard is the appropriate objective. Further, the NAS study concludes that excess weapon plutonium constitutes a "clear and present danger" and emphasizes the need to dispose of weapon plutonium "sooner rather than later." With this objective and philosophy, NAS recommended, as most promising, the use of weapon plutonium as fuel in existing power reactors in the United States, Canada, Russia, Europe, and Japan.

My presentation today reviews the application of U.S. LWRs that are loaded with all-MOX fuel to dispose of excess weapon plutonium. The information that I present is based on the DOE study results summarized in the 1993 DOE report, ${ }^{4}$ and the detailed reports ${ }^{6-8}$ submitted by the reactor designers to DOE for that report. Analysis of published information in the nuclear community is the basis for an estimate of the capabilities of existing LWRs to switch from low-enriched uranium (LEU) to all-MOX fuel. 


\section{Reactor Designs Considered}

Two evolutionary and one advanced reactor designs by three U.S. reactor designers, as well as their newer designs that are in commercial operation, are discussed here. These reactors allow core loadings of all-MOX fuel.

The commercial version of the advanced reactor design by Westinghouse Electric Corp. is known as the (Advanced Passive) AP600, and its plutonium disposition counterpart is called the (Plutonium Disposition Reactor) PDR600. These reactors produce nominally $600 \mathrm{MW}_{\mathrm{e}}(1930 \mathrm{MW})$. The standard safety analysis report and the probability risk assessment were submitted to the Nuclear Regulatory Commission (NRC) in June 1992. Final design approval by NRC is expected in September 1996. If it were decided to use the PDR600, supplementary analyses would be submitted to NRC so that use of weaponderived MOX fuel could be included in the resulting license.

The GE Nuclear Energy advanced (but considered evolutionary) boiling water reactor (ABWR) received final design approval from the NRC last July. Two of these plants, each to produce nominally $1300 \mathrm{MW}_{\mathbf{e}}\left(3925 \mathrm{MW}_{t}\right)$ using (LEU) fuel, are under construction in Japan. MOX fuel for the ABWR is designed to be interchangeable with standard LEU fuel. This is achieved by minimizing the difference in reactivity as a function of burnup and on control blade worth while maintaining reasonable peak-to-average power ratios.'

The ABB-Combustion Engineering evolutionary reactor design, System 80+, builds on simplifications and improvements applied to the System 80 design. The commercial version produces $1300 \mathrm{MW}_{\mathbf{e}}\left(3915 \mathrm{MW}_{\mathrm{t}}\right)$. Final design approval was obtained from NRC also last July. To provide the same thermal margins when the reactor is converted to MOX fuel, the thermal power is reduced to $3800 \mathrm{MW}$, thus reducing the net electric power to $1250 \mathrm{MW}$.

Late-model LWRs could be used for plutonium disposition. Estimates of performance are based on the characteristics of the evolutionary/advanced LWR designs and general published data, including Ref. 9. 


\section{Reactor Disposition Performance}

The general disposition performance of three new LWRs that use MOX fuel made from weapon plutonium ${ }^{4,6-8}$ is shown in Table 1 . For this discussion, the amount of excess weapon plutonium for dispositioning is assumed to be $50 \mathrm{Mg}$. Larger amounts could be accommodated. Except for the advanced PDR600 reactor, these reactors generate electricity well above the $1000-\mathrm{MW}_{\mathrm{e}}$ level. Because different optimization objectives were used for these designs, the difference in disposition performance is not necessarily an inherent characteristic of the reactor design. Rather, the data should be taken to indicate a general capability of LWRs as a class. For example, the longer disposition times associated with the ABWR result from an attempt to better match the plutonium content in the spent fuel with that from LEU spent fuel, as shown in Table 2. The energy utilization of plutonium in the ABWR design of Table 1 is much higher than for the other reactors. It is clear that the choice of reactor for plutonium disposition will depend on many considerations, one being a tradeoff in plutonium energy utilization and high plutonium throughput in the reactor.

Table 1. Disposition capability of new LWRs using all-MOX fuel.4,6-8

\begin{tabular}{|c|c|c|c|}
\hline Capability & $\begin{array}{c}\text { ABB-CE } \\
\text { System } 80+\end{array}$ & $\begin{array}{c}\text { GE } \\
\text { ABWR }\end{array}$ & $\begin{array}{c}\text { Westinghouse } \\
\text { PDR600 } \\
\end{array}$ \\
\hline Thermal power (MW) & 3800 & 3026 & 1933 \\
\hline Electric power (MW) & 1256 & 1297 & 600 \\
\hline Burnup (MW/day $/ \mathrm{kg}$ of heavy metal) & 42.2 & 37.1 & 40 \\
\hline Initial Pu/heavy metal content (\%) & 6.8 & 3.0 & 5.5 \\
\hline Final Pu/heavy metal content (\%) & 5.1 & 1.9 & 3.9 \\
\hline Reactor throughput (kg Pu/y) & 1668 & 867 & 725 \\
\hline Reactor throughput (Mg of heavy metal/y) & 24.7 & 28.9 & 13.2 \\
\hline Disposition time $(y)^{b}$ & 30.0 & 57.7 & 69.0 \\
\hline Electric energy (GW/y) & 28.2 & 56.1 & 31.0 \\
\hline Specific electric energy (MW.y/kg Pu) & 0.56 & 1.12 & 0.62 \\
\hline Normalized disposition time ${ }^{c}$ & 1.00 & 1.99 & 1.17 \\
\hline $\begin{array}{l}\text { No. of reactors needed to dispose of } \\
50 \mathrm{Mg} \text { in }<10 \mathrm{y}\end{array}$ & 3 & 6 & 7 \\
\hline
\end{tabular}

a Capacity factor assumed to be $75 \%$.

b Disposition time for one reactor to process $50 \mathrm{Mg}$ of $\mathrm{Pu}$.

c Normalized disposition time is the product of thermal power times disposition time divided by the smallest of these products. 
Table 2. Comparisons of plutonium composition in spent fuel (\%), $4,6-8$

\begin{tabular}{|c|c|c|c|c|}
\hline & System 80+ & ABWR & PDR600 & $\begin{array}{c}\text { Typical } \\
\text { LWR }^{\mathbf{a}}\end{array}$ \\
\hline Fuel & MOX & MOX & MOX & $\overline{\text { LEU }}$ \\
\hline Burnup (MW.d/kg of heavy metal) & 42 & 37 & 40 & N/A \\
\hline Pu-238 & 0.0 & 0.9 & 0.6 & 2 \\
\hline Pu-239 & 63.1 & 42.3 & 59.7 & 58 \\
\hline Pu-240 & 22.7 & 35.4 & 24.3 & 23 \\
\hline $\mathrm{Pu}-241$ & 12.6 & $\mathbf{1 4 . 7}$ & 13.3 & 13 \\
\hline Pu-242 & 1.7 & 6.7 & 2.2 & 4 \\
\hline Total Pu (kg of Pu/kg of heavy metal) & 5.1 & 1.9 & 3.9 & 1 \\
\hline
\end{tabular}

a Data in Ref. 4 was adjusted to show typical ${ }^{238} \mathrm{Pu}$ content and Pu content in heavy metal.

The isotopic distributions for MOX spent fuel in the evolutionary/advanced LWRs are shown in Table 2 for MOX fuel and for typical LWRs using LEU fuel. Note that, for practical purposes, the isotopic distributions in the spent fuel are similar. The most significant difference is that spent fuel from the plutonium disposition operation can contain a higher fraction of plutonium, resulting from the desire to speed up the disposition process. This higher plutonium content in the spent fuel generated by the disposition process should be acceptable because the remaining quantity of plutonium in all of the spent fuel would be small (less than $5 \%$ ) compared to the amount contained in the world's accumulation of commercial spent fuel.

It seems entirely reasonable to postulate that some amount of plutonium can be loaded into each fuel element of an existing reactor. After all, plutonium is produced in each fuel element during its cycle in the reactor to such an extent that the discharged fuel contains about $1 \%$ plutonium in heavy metal (see Table 2). The perception that only one-third of a reactor core can be loaded with plutonium must be attributed to other reasons. For example, it would be more economical to fabricate one-third as many fuel assemblies containing three times as much plutonium as it would be to fabricate the converse situation. Also, older reactors do not provide as many control rod locations as do late-model LWRs.

Over 50 late-model LWRs are in operation in the United States. From among these it should be possible to synthesize a group of reactors that could 
accomplish the disposition mission. Ideally, to simplify safeguard issues and to benefit from shared facilities, the group selection should minimize the number of reactor sites, owners, and types of reactors. Cumulative remaining licensed life for these reactors can be inferred ${ }^{9}$ to be greater than 1000 years. A rough approximation of the capabilities of existing reactors for plutonium disposition can be obtained from a simplified approach based on the LEU fuel cycle. The following parameters were assumed for this analysis:

Thermal power (MW)

Electric power (MW)

Capacity factor 0.75

Efficiency

Burnup (MW.d $/ \mathrm{kg}$ of heavy metal)

Reactor fuel throughput (Mg of heavy metal/yr) 28

Excess weapon plutonium to disposition $(\mathrm{Mg})$

50

Figure 1 shows the annual throughput as a function of plutonium content in heavy metal. (The range of plutonium content in heavy metal is considered here to be 3 to $7 \%$.) Each specific content would require thorough analysis to determine performance, core material additives, and control characteristics.

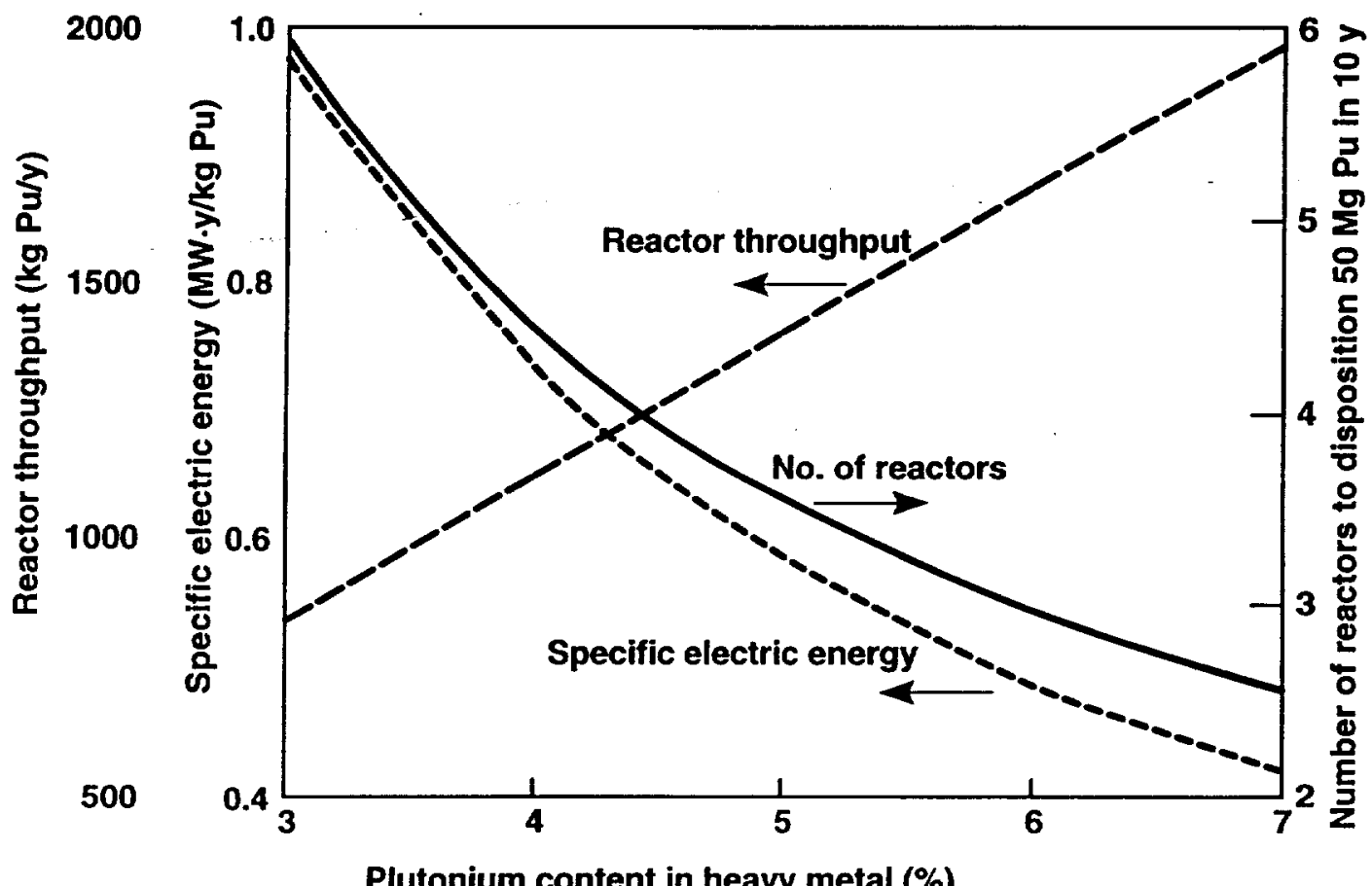

Figure 1. Postulated parametric disposition capability of existing LWRs using all-MOX fuel. 
The heavy metal throughput and the burnup are held constant in this approximation.

Figure 1 also shows the number of reactors required for disposition of $50 \mathrm{Mg}$ of plutonium in 10 years. From this analysis, it appears that a reasonably small number of reactors is required, even at the lower end of plutonium content. As plutonium content increases, the number of reactors needed decreases, but so does the amount of electricity produced (at constant burnup).

\section{Feed Material for MOX Fuel}

Recovery of plutonium from dismantled weapons and other weapon program residues, is a necessary first step for plutonium disposition. Whether used as fuel in reactors or mixed with radioactive waste and placed in a glass matrix for permanent geological storage (called vitrification), the form of choice would appear to be $\mathrm{PuO}_{2}$. Because of the urgency attached to the disposition of plutonium, this work should begin at once, even before the method of disposition is decided.

The recovery process should provide $\mathrm{PuO}_{2}$ powder with the appropriate morphology to permit dry blending with $\mathrm{UO}_{2}$ powder in the fabrication of MOX fuel. This approach results in reduced waste streams, and therefore is environmentally preferable. Weapon plutonium will contain ${ }^{241} \mathrm{Am}$ at concentrations dependent on the time elapsed since the plutonium was separated. Americium, resulting from the 14.4 -year half-life decay of ${ }^{241} \mathrm{Pu}$ is troublesome because of its relatively high activity of, principally, $60-\mathrm{keV}$ gamma radiation. However, the concentration of ${ }^{241} \mathrm{Am}$ should not exceed $0.5 \%$ in weapon plutonium. When blended with $\mathrm{UO}_{2}$ at the plutonium concentrations anticipated, the effective concentration of ${ }^{241} \mathrm{Am}$ will be reduced to less than $0.03 \%$. Since much of the MOX fabrication process will likely be performed remotely, radiation exposure to workers should be below established limits. (The americium concern is considerably greater when reactor-grade plutonium is used to make MOX fuel, because the concentration of ${ }^{241} \mathrm{Pu}$ is of the order of $10 \%$, as shown in Table 2.) 


\section{Characteristics of MOX-Fueled LWRs}

MOX-fueled and LEU-fueled reactors have a number of differences in core characteristics. The basic differences in their nuclear properties-such as neutron lifetime, delayed neutron fraction, and cross sections-produce neutronic performance differences such as reactor kinetics that result from altered temperature and power coefficients, reactivity margins, and material behavior. It appears that adjustments for these differences can be made such that the only licensing action needed is a supplementary amendment to the LEU-fueled reactor with regard to the MOX fuel form.

Plutonium disposition is accelerated by the ability to increase the fraction of plutonium in MOX fuel. The use of depleted uranium (from earlier enrichment tails inventories) allows a higher plutonium fraction for a given reactivity worth of the fuel. To compensate for the added reactivity in the reactor that is introduced in pursuit of this objective, burnable neutron absorbers are needed. This is not an unpracticed technology, however, as the same is already done to accommodate the higher enrichment in LEU fuels that achieve higher burnup.

Several absorbers may be used. ABB-Combustion Engineering uses $\mathrm{Er}_{2} \mathrm{O}_{3}$, and GE Nuclear Energy prefers $\mathrm{Gd}_{2} \mathrm{O}_{3}$. These rare-earth oxides are blended directly into the MOX fuel. Westinghouse uses boron in the form of a $\mathrm{ZrB}_{2}$ coating on the surface of the MOX fuel pellets. Discrete absorbers are also used in some cases in replacement "fuel" rods in the fuel assembly.

Finally, a higher control worth is needed. Worth may be increased by providing more control rods or providing higher-worth rods. The evolutionary/advanced reactors have enough control rod positions to do this. However, to avoid modifying existing reactors that may be used for plutonium disposition, it may be necessary to increase control rod worth.

MOX fuel fabrication is fairly well understood, and minimal development is expected to be needed. Nevertheless, it seems appropriate to conduct fabrication/performance demonstrations with the prototypical fuel material. 
This work should commence right away, even if another method of disposition is eventually chosen.

\section{Environmental Considerations}

The environmental burdens associated with operation of LWRs fueled with LEU have been shown to be minimal. ${ }^{10}$ Using weapon-derived MOX instead of LEU fuel in LWRs to dispose of plutonium while producing electricity will, in fact, show a beneficial impact on the environment. Plutonium disposition operations in LWRs avoid mining, milling, conversion (to $\mathrm{UF}_{6}$ ), and enrichment of uranium and therefore can be credited with beneficial impact to that extent. In addition, a use is created for existing stockpiles of enrichment tails-perhaps about $1000 \mathrm{Mg}$.

\section{Conclusions}

This discussion strongly indicates that disposition of plutonium in a reasonable number of LWRs is feasible, using all-MOX fuel assemblies. Principal conclusions are as follows:

- Operations to recover plutonium from the excess inventory and convert it to $\mathrm{PuO}_{2}$ should commence immediately because $\mathrm{PuO}_{2}$ is the form likely needed for most of the viable disposition methods and because of the urgency of the disposition effort. Because the recovery process provides feed material for reactor fuel, it can constrain the disposition schedule.

- Another long-lead item that should be initiated at once is the fabrication, testing, and examination of lead test assemblies (LTAs) containing prototypical MOX fuel. MOX fuel fabrication can be carried out in laboratory-scale systems. Irradiation would best be carried out in existing operational LWRs. Post-irradiation examination should be performed to confirm the expected fuel performance.

- Weapon plutonium can be made into spent fuel in evolutionary and advanced reactors constructed especially for this purpose and loaded with all-MOX fuel. 
- Existing LWRs of later design (and longer remaining life) should be capable of safe operation with significant core loadings of all-MOX fuel. The United States appears to have enough existing reactors to dispose of plutonium in as short a time as desired, subject to the availability of plutonium recovery and fuel fabrication capability.

- Disposition of weapon plutonium by using it in MOX fuel in a reactor while producing electric power has a beneficial effect on the environment, even when compared to the already small impact of the LEU fuel cycle.

- An examination of Russia's Vodo-Vodianoi Energetitchecki Reactor . (VVER) (water-cooled, water-moderated energy reactor)—comparable to the evaluation of existing U.S. LWRs currently in progress by DOEshould be performed to determine the potential for rapid disposition of excess weapon plutonium in VVERs.

\section{Acknowledgment}

This work was performed by the Lawrence Livermore National Laboratory under the auspices of the U.S. Department of Energy under Contract No. W7405-Eng-48.

\section{References}

1. W. G. Sutcliffe, "Fissile Materials from Nuclear Arms Reductions: A Question of Disposition," Proceedings for Session 35T-2 of the Annual Meeting of the American Association for the Advancement of Science, Washington, DC, Lawrence Livermore National Laboratory, Livermore, CA, CONF-910208, CTS-31-92 (February 18, 1991).

2. R. P. Koopman et al., Disposition of Plutonium and Highly Enriched Uranium from Nuclear Weapons, Part I-Issues and Options, Lawrence Livermore National Laboratory, Livermore, CA, Draft Report (December 23, 1992).

3. R. P. Omberg and C. E. Walter, Disposition of Plutonium from Dismantled Nuclear Weapons: Fission Options and Comparisons, 
Lawrence Livermore National Laboratory, Livermore, CA, UCRL-ID113055 (February 5, 1993).

4. Plutonium Disposition Study, U.S. Department of Energy, Washington, DC, Technical Review Committee Report, Vols. I and II (July 2, 1993).

5. Management and Disposition of Excess Weapon Plutonium, Committee on International Security and Arms Control, National Academy of Sciences (National Academy Press, Washington DC, 1994).

6. DOE Plutonium Disposition Study-Pu Consumption in ALWRs, Contract No. DE-AC03-93 SF19682, ABB-Combustion Engineering, Windsor, CT, Final Report, Vols. I and II (May 15,1993).

7. Study of $\mathrm{Pu}$ Consumption in Advanced Light Water Reactors, Contract RFP DE-AC-03-93SF19681, GE Nuclear Energy, San Jose, CA (May 13, 1993).

8. PDR600-Plutonium Disposition Study, Contract DE-AC03-93SF-19683, Westinghouse Electric Corporation, Pittsburgh, PA, May 15, 1993.

9. World Nuclear Industry Handbook 1994, Nuclear Engineering International (1994).

10. Environmental Survey of the Uranium Fuel Cycle, U.S. Atomic Energy Commission, Washington, DC, WASH-1248 (April 1974). 
$\cdot \ldots$ 


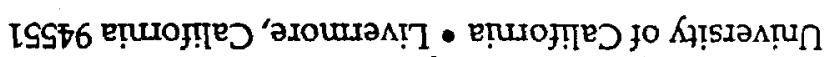

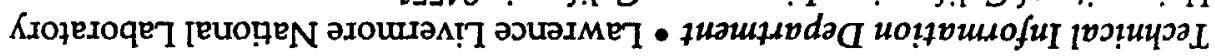

